\title{
Thin melanoma and sentinel lymph node biopsy: A difficult relationship between them
}

JC Rodriguez Otero ${ }^{1}$, R Fernández Bussy ${ }^{2}$, A Bergero ${ }^{2}$, M Gorosito ${ }^{2}$, G Salerni ${ }^{2}$, MS Dagatti ${ }^{2,3}$, R Villavicencio ${ }^{4}$, R Staffieri ${ }^{4}$, SM Batallés ${ }^{4}$, V Milatich $^{4}$, J Rodriguez Otero $^{3}$, SM Pezzotto ${ }^{3,5 *}$ and GEMRO (Grupo de Estudio de Melanoma Rosario)

${ }^{1}$ Cátedra de Cirugía, Facultad de Ciencias Médicas, Universidad Nacional de Rosario (UNR), Argentina

${ }^{2}$ Cátedra de Dermatología, Facultad de Ciencias Médicas, UNR, Argentina

${ }^{3}$ Área Metodología de la Investigación Científica, Facultad de Ciencias Médicas, UNR, Argentina

${ }^{4}$ Grupo Oroño, Argentina

${ }^{5}$ Instituto de Inmunología Clínica y Experimental de Rosario, IDICER-CONICET, Facultad de Ciencias Médicas, UNR, Argentina

\begin{abstract}
Introduction: Cutaneous Melanoma $(\mathrm{CM})$ is one of the few malignancies with increasing incidence and mortality rates. The most significant increase was observed in 'thin' melanomas $(\mathrm{TM})$ (Breslow $\leq 1 \mathrm{~mm})$. A low percentage of these patients may present a late recurrence, progression, and death.

Purpose: Our primary objective was to show the relationship between patients who suffer from thin melanoma with the predictors of the illness. Our secondary objective was to note the survival according to lymph node biopsy results.

Materials and methods: Histopathologically proved CMs with a Breslow thickness $\leq 1 \mathrm{~mm}$ were retrospectively reviewed from January 2000 to December 2015 . The CMs were classified using the AJCC Staging System (2010). In cases where CMs had a Breslow thickness $\leq 1 \mathrm{~mm}$ and were associated with ulceration, mitotic rate $(\mathrm{MR})$ per $\mathrm{mm}^{2}>0$, Clark level $\geq \mathrm{IV}$, satellitosis, angiolymphatic or perineural invasion, it was suggested to biopsy the sentinel lymph node (SLN) status were compared and divided into two groups, according to the results and the survival analysis.

Results: 265 of the 642 patients with CM (41.3\%) had a Breslow thickness $\leq 1 \mathrm{~mm}$, and 65 of them (24.5\%) had also ulcerations or a MR $>0$ or Clark $\geq$ IV. Furthermore, $10.8 \%$ had a positive SLN. Clark level $\geq \mathrm{IV}$ was associated with a positive SLN ( $\mathrm{p}=0.035$ ). There was a clear difference in the survival distributions according to the lymph node status $(\rho=0,014)$.
\end{abstract}

Conclusions: The sentinel lymph node status was important for the patient progress.

Abbreviations: AJCC: American Joint Committee on Cancer, CM: Cutaneous Melanoma, GEMRO: Grupo de estudio de Melanoma Rosario (Rosario Melanoma Study Group), HE: Hematoxylin-Eosin, IHQ: Immunohistochemistry, MM: Malignant Melanoma, MR: Mitotic Rate, OS: Overall Survival, SD: Standard Deviation, SLN: Sentinel Lymph Node, SLNB: Sentinel Lymph Node Biopsy, SMU: Sydney Melanoma Unit, TM: Thin Melanoma

\section{Introduction}

Malignant melanoma is one of the tumors having an increasing annual incidence rate over the past 40 years. The significant increase was observed in thin melanomas, which represent $65 \%-80 \%$ of the total diagnosed melanomas [1,2].

Although the prognosis is very good, a $10 \%$ of these patients present a late recurrence, progression, and death.

The sentinel node was defined by Morton et al. (1992) [3] as an intermediate-thickness melanoma, and this concept was a subject of controversy for clinical indications in thin melanoma group studies.

Our primary objective was to show the relationship between patients who suffer from thin melanoma with the predictors of the illness. Furthermore, we studied the sentinel lymph node (SLN) in order to identify groups at higher risk of having lymph node deposits.
Our secondary objective was to note the survival according to lymph node biopsy results.

\section{Materials and methods}

From January 2000 to December 2015 we retrospectively reviewed all melanomas hispathologically proved, with a Breslow thickness $\leq 1 \mathrm{~mm}$ and referred to Grupo de Estudio de Melanoma Rosario (GEMRO) for surgical treatment. The GEMRO is composed by health professionals who belong to Surgery, Dermatology and Pathology Department in the following institutions: Facultad de Ciencias Médicas -Universidad Nacional de Rosario-, Instituto Cardiovascular Rosario and Diagnóstico Médico Oroño.

Melanomas were classified using the AJCC Staging System (2010) [4] including age, gender, location, histological type, Breslow thickness, Clark levels, presence or absence of ulceration, and mitotic rate per $\mathrm{mm}^{2}$.

Correspondence to: Prof. Stella Maris Pezzotto, Facultad de Ciencias Médicas, Universidad Nacional de Rosario (UNR), Santa Fe 3100, 2000 Rosario, Argentina, E-mail: spezzot@unr.edu.ar

Key words: thin melanoma, sentinel lymph node, predictor factor

Received: December 09, 2016; Accepted: December 27, 2016; Published: December 29, 2016 


\section{Cases of melanoma in situ were excluded.}

The study of SLN was indicated in cases where melanomas had a Breslow thickness $\leq 1 \mathrm{~mm}$, and were associated with some of the following factors: ulceration, mitotic rate per $\mathrm{mm}^{2}>0$, Clark level $\geq \mathrm{IV}$, marked regression, satellitosis, and angiolymphatic or perineural invasion. In all cases, the margin resection was $\geq 1 \mathrm{~cm}$ for primary tumors.

The procedure was performed with the integration of the following three phases:

a) Preoperative determination of regional lymph nodes along with the estimation and localization of sentinel lymph nodes (dynamic isotope lymphography). For performing the lymphography, we administered between 2 and 4 intradermal injection at equidistant points in the cutaneous lesion, or in the previous scar of surgical removal, at approximately $1 \mathrm{~cm}$ perilesional area or in the excisional biopsy site, with $0.1 \mathrm{ml}$ solution of $100-500 \mu \mathrm{Ci}$ of $99 \mathrm{mTc}-$ albumin nanocolloid (particles range from 0.05 to 0.8 microns). Subsequently, a digital light massage was performed to promote the absorption of tracer in the lymphatic channels and its flow. Next, still images were obtained at anterior, posterior and lateral position, depending on the anatomical area of the lesion. Once the sentinel lymph node was located, it was performed a mark on the skin. Afterwards, metabolic tomographic images (SPECT Infinia Hawkeye 4 General Electric') were obtained using a circular orbit at $360^{\circ}$, and then TC images were acquired. With the algorithm available, images from the SPECT and TC were merged. At the end, multiplanar reconstructions were performed.

b) Intraoperative localization and sentinel lymph node biopsy (lymphatic mapping). The lymphatic mapping was performed with an intraoperative detection device for sentinel lymph node (radio guided surgery detection DGC-II Gamma Probe NuclearLab SRL). This device comprises a gamma rays detection system with a small probe of an optimal sensitivity that enables the radio guided surgery and the accurate identification of marked tissue. The probe was sterilized before surgical incision. The area was identified through the probe to maximum count intensity in the lymph node surface area, and the exact location where the incision would be performed, was stained with permanent ink. Once the lymph node was resected, the measurement of radioactivity in the biopsy was performed, and a trace of the nodal area was conducted. In most medical studies, it is considered that sentinel lymph node must have a background activity rate higher to 3 to 1 in vivo, and higher to 10 to 1 ex vivo.

c) Histopathology. Histopathological samples were stained with hematoxylin-eosin (HE). If the result was negative, samples were studied with IHQ (Melan-A, HMB 45). When samples were negatives at both examinations, it was considered that the final result was, in fact, negative. All patients with thin melanoma who had a sentinel lymph node biopsy were compared and divided into two groups, according to the biopsy result. The overall survival was analyzed depending on the final nodal result.

\section{Statistical analysis}

For descriptive purposes, valid percentages (percentages based on sample size excluding missing values) were calculated. The association between sentinel lymph node biopsies (SLNB) and categorical variables were compared using chi square test or Fisher's exact test, as appropriate. Quantitative variables were expressed as mean \pm standard deviation. The $t$-test was used to compare mean differences. Probability of survival was computed using Kaplan-Meier method.
Log Rank test was used to evaluate the equality of survival distributions in the different levels of SLNB. A two-sided $\rho$ value of 0.05 or less was considered to be statistically significant. All data analyses were performed using Stata statistical software.

\section{Results}

From January 2000 to December 2015, 642 patients ranged from 22-77 years (mean 49.4 years) with CM were studied retrospectively. Among them, 265 (40\%) presented thin melanomas proved, and 65 of them (24.5\%) had a Breslow thickness $\leq 1 \mathrm{~mm}$, with ulcerations or $\mathrm{MR}>0$ or Clark $\geq \mathrm{IV}$, consequently, it was decided to study the sentinel lymph node. The follow-up time ranged from 12 to 120 months, mean 40 months, and interquartile range 18-73 months. Table 1 shows general data from all patients and the sentinel lymph node results.

Sentinel lymph node results and their relation to the different histopathologic studies with predictor factors. None of the thin melanomas had angiolymphatic invasion, neurotropism, or satellitosis (Table 2).

At the end of the follow-up time, only 5 patients had died during the study because of the illness. Of these patients, 3 presented a positive sentinel lymph node.

The Kaplan-Meier survival curves for the length of time until death

Table 1. General data.
\begin{tabular}{|l|c|c|c|c|}
\hline & Total: n (\%) & SLN (-) & SLN (+) & \\
\hline Patients & $65(100)$ & $58(89.2)$ & $7(10.8)$ & \\
\hline Age & & & & \\
\hline Mean \pm SD & $49.6 \pm 13.7$ & $48.9 \pm 13.1$ & $55.1 \pm 18.8$ & $\rho=0.262$ \\
\hline Gender & & & & \\
\hline Male & $23(35.4)$ & $19(82.6)$ & $4(17.4)$ & $\rho=0.194$ \\
\hline Female & $42(64.6)$ & $39(92.9)$ & $3(7.1)$ & \\
\hline Localization & & & & \\
\hline Body & $33(49.2)$ & $29(50.0)$ & $3(42.9)$ & $\rho=0.781$ \\
\hline Lower Limb & $18(27.7)$ & $15(25.9)$ & $3(42.9)$ & \\
\hline Upper Limb & $13(20.0)$ & $12(20.7)$ & $1(14.3)$ & \\
\hline Head and Neck & $2(03.1)$ & $2(03.4)$ & 0 & \\
\hline
\end{tabular}

Table 2. Histopathology and predictor factors.

\begin{tabular}{|c|c|c|c|c|}
\hline & Total: n (\%) & SLN (-) & SLN (+) & \\
\hline Histological Type & & & & \\
\hline Superficial Spreading & $39(60.0)$ & $34(58.6)$ & $5(71.4)$ & $\rho=0.282^{*}$ \\
\hline Nodular & $5(07.7)$ & $5(08.6)$ & 0 & \\
\hline Acral Lentiginous & $3(04.6)$ & $2(03.4)$ & $1(14.3)$ & \\
\hline Others & $11(16.9)$ & $11(19.1)$ & 0 & \\
\hline No data & $7(10.8)$ & $6(10.3)$ & $1(14.3)$ & \\
\hline Breslow Thickness & & & & \\
\hline$<0.5$ mm & $3(04.6)$ & $3(05.2)$ & 0 & $\rho=0.704$ \\
\hline $0.5-0.75$ & $14(21.5)$ & $13(22.4)$ & $1(14.3)$ & \\
\hline$>0.75-1.0$ mm & $48(73.8)$ & $42(72.4)$ & $6(85.7)$ & \\
\hline Clark Levels & & & & \\
\hline II-III & $57(87.7)$ & $53(91.4)$ & $4(67.1)$ & $\rho=0.035$ \\
\hline IV-V & $8(12.3)$ & $5(08.6)$ & $3(42.9)$ & \\
\hline Mitotic Rate (n/mm $)$ & & & & \\
\hline 0 & $9(13.8)$ & $8(13.6)$ & $1(16.7)$ & $\rho=0.607$ \\
\hline$\geq 1$ & $56(86.2)$ & $51(86.4)$ & $5(83.3)$ & \\
\hline Ulceration & & & & \\
\hline Present & $19(29.2)$ & $16(27.6)$ & $3(42.9)$ & $\rho=0.331$ \\
\hline Absent & $46(70.8)$ & $42(72.4)$ & $4(57.1)$ & \\
\hline & & & & \\
\hline
\end{tabular}

*No data patients were excluded 
are presented for the positive and negative patients groups (Figure 1). A Tarone-Ware test was run to determine if there were differences in the survival distribution by SLNB. The survival distributions for the two groups were statistically significantly different $(\rho=0,014)$.

The Kaplan-Meier estimates of survival data are shown in Table 3. There was a significant difference in survival times between both groups. $(\rho=0.001)$.

\section{Discussion}

The increased incidence rate of melanomas is based on the special group of thin melanomas, which represents between $60 \%$ and $80 \%$ of total $[1,2,5-10]$. Despite its good prognosis, this group is responsible for $15 \%-30 \%$ of melanoma deaths $[6,7,11,12]$. Because of this casual connection, it is essential to try to identify the high-risk group which may develop regional lymph node deposits.

The predictor factor in the SLNB in intermediate-thickness melanoma is well accepted, but its value for patients with thin and thick lesions is being discussed [13-15].

The broad range of reported SLN positive rates in thin melanoma patients estimates between $0 \%$ and $18 \%$, especially with the use of selection criteria $[1,16-32]$. In our study, the estimate was $10.8 \%$ in thin melanomas including sentinel lymph node biopsy.

The risk of lymph node progression increases in young adults, however, the survival decreases as age increases $[16,33,34]$.

Older people ( \pm 65 years old) also can have lymphatic functional disorder [25]. A recent study of lymphoscintigraphy data from 858 patients undergoing SLNB, showed that mean radioactive counts of SLNs were inversely related to age. This suggests that older patients may have altered lymphatic function resulting in a lower rate of SLNB positive, but worse the overall survival (OS) [35].

Table 3. Kaplan Meier estimates of survival data.

\begin{tabular}{|l|c|c|}
\hline & Mean \pm Standard Error & $\mathbf{9 5 \%}$ Confidence Interval \\
\hline Negative & $117.5 \pm 2.5$ & $112.7-122.3$ \\
\hline Positive & $82.8 \pm 9.7$ & $63.9-101.7$ \\
\hline Global & $110.4 \pm 4.5$ & $101.6-119.2$ \\
\hline
\end{tabular}

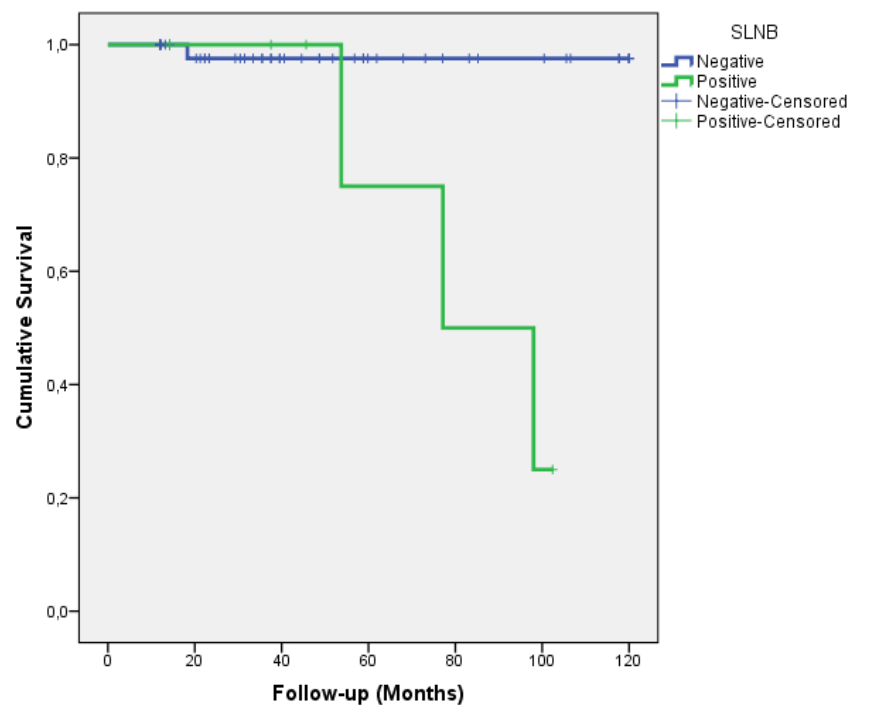

Figure 1. Kaplan-Meier survival curves.
In most articles, the average age ranged from 47 to 54 years, but in our study it was $22-77$ years (mean 49.4 years) [34].

Some authors found that men are in greater proportion placed in the high-risk subset $[36,37]$. In our experience, it was a clear prevalence of men.

It is obvious that a $>0.75 \mathrm{~mm}$-thick-melanoma has greater probabilities to be related with a positive sentinel lymph node, especially when is associated with a Clark IV, an ulceration present, or a mitotic rate $\geq 0[19,27,38]$. However, it is difficult to predict which patient with that thickness may yield a positive result $[27,39]$.

A significant number of authors suggests that is not necessary to conduct a sentinel lymph node biopsy to melanomas with a thickness $\leq 0.75 \mathrm{~mm}$, since is unlikely that they yield a positive result $[26,27,38,40]$.

Lesions less than $0.75 \mathrm{~mm}$ in depth have a reported rate of distant metastasis in the range of $1 \%$ or $2 \%$ to $5.5 \%$ [ $41-45]$.

Wright et al. (2008) presented 178 cases $\leq 0.5 \mathrm{~mm}$ with a sentinel lymph node biopsy performed that yield a positive result in 8 (4.4\%), and one of them had a thickness lower to $0.25 \mathrm{~mm}$ [46]. Moreover, there are some articles that refer to a positive result in melanomas $<0.50 \mathrm{~mm}$ thickness, which is an adverse predictor [47,48]. In our study, we found 16 patients with melanomas with a thickness $\geq 0.75$ $\mathrm{mm}, 3$ of which were lower than $0.5 \mathrm{~mm}$ and 1 yield a positive result. Therefore, it is questionable the approach that there is not necessary to perform a SNLB $<0.5 \mathrm{~mm}$ based only on the concept of thickness.

In the seventh edition of the AJCC Staging, mitotic rate has replaced Clark levels of invasion [4].

The possibility for detecting a thin malignant melanoma with a Clark level $\geq$ IV ranged from 5 to $18 \%[1,8,16,36,49-51]$.

In a review of 7331 invasive primary melanomas $\leq 1.0 \mathrm{~mm}$ thick, 1320 (18\%) were reported to be Clark level IV in the Sydney Melanoma Unit (SMU). When level IV invasion is present, the prognosis is known to be worse than for other thin tumors $[41,43]$.

The potential for a thin melanoma Clark level $\geq$ IV presented a positive sentinel lymph node was $4.7 \%-14 \%$ [1,8,16,51-53].

In our study, 3 of 8 patients (12.3\%) with a Clark level $\geq \operatorname{IV}$ presented a positive sentinel lymph node, which was considered statistically significant.

In malignant thin melanomas, ulceration is present in $1.6 \%-6 \%$ of cases $[1,5,21,22,25,54]$. Numerous authors suggest that when ulceration is present, it is a clear sign of a predictive factor for positive sentinel lymph node $[55,56]$.

Han et al. (2013) have proposed that ulceration rates in thin MM ranged from $1-15 \%$, and this wide variation may be due, in part, to the fact that ulceration is uncommon and that a few patients may have had local trauma and been incorrectly classified as ulcerated. In our case study, 29.2\% presented ulceration [8].

Mitotic rate as a prognostic attribute was first introduced into the literature by Cochran (1968) [57]. In our study, the mitotic rate (n/ $\mathrm{mm}^{2}$ ) was 0 in 9 patients, 8 of which had a negative SLN while the other one had a positive SLN. In 56 subjects, the mitotic rate was $\geq 1$, and 51 of these patients had a negative SLN while 5 a positive SLN. Numerous studies had tried to define the subset of patients with a melanoma $\leq 1.0$ $\mathrm{mm}$, which are prone to have a positive SLN. Many authors had found that mitotic activity is a predictive factor to have a positive SLN, while 
others had not found any relation between them. In our experience, this was not a positive predictive factor in melanomas Breslow $\leq 1$.

Thompson et al. (2011) suggests that the 10-year survival for patients with thin melanoma and dermal mitotic activity ranges from $48 \%$ to $89 \%$, compared with $93 \%$ patients with thin melanoma without a dermal mitotic activity [25].

Many studies have attempted to define the subset of patients with melanoma less than or equal to $1.0 \mathrm{~mm}$, who are most likely to have a positive SLNB. Primary tumor thicknesses of greater than $0.75 \mathrm{~mm}$ are generally considered to pose a higher risk for nodal metastasis $[17,54,58]$. Some authors have found mitotic activity to be predictive of a positive SLN in their studies, whereas others did not $[1,2,7,8,17,28,33,55,58,59]$.

Multiple studies have recently shown that SLN positive is not associated with poorer disease free survival in patients with thin melanoma $[1,26,60]$. Studies that explored the risk of a positive SLN, but did not include follow-up data, were excluded from consideration. This represents a particularly problematic constraint for studies of SLN biopsy in patients with thin melanomas, where a follow-up of a decade or more is required to assess the prognostic impact of regional nodal staging [61].

In our study, there was a clear difference in patients' survival depending on the sentinel lymph node status. We consider that is not necessary to study the sentinel lymph node in all thin melanomas, because most of them may yield a negative result. However, taking into account all the predictive factors including the thickness could define the number of studies and thus achieve results more accurately with the predictive value in the sentinel lymph node status.

\section{Acknowledgments}

The authors acknowledge Mariana Sedliak for improving writing in the English language.

\section{References}

1. Wong SL, Brady MS, Busam KJ, Coit DG (2006) Results of sentinel lymph node biopsy in patients with thin melanoma. Ann Surg Oncol 13: 302-309. [Crossref]

2. Andtbacka RH, Gershenwald JE (2009) Role of sentinel lymph node biopsy in patients with thin melanoma. J Natl Compr Canc Netw 7: 308-317. [Crossref]

3. Morton DL, Wen DR, Wong JH, Economous JS, Cagle LA, et al. (1992) Technica details of intraoperative lymphatic mapping for early stage melanoma. Arch Surg 127: 392-399. [Crossref]

4. Compton CC, Byrd DR, García-Aguilar J, Kurtzman SH, Olawaiye A, et al. (2012) AJCC Cancer Staging Atlas: A Compainion to the Seventh Editions of the AJCC Cancer Staging Manual and Handbook, 2nd Ed. Springer, New York.

5. Faries MB, Wanek LA, Elashoff D, Wright BE, Morton DL (2010) Predictors of occult nodal metastasis in patients with thin melanoma. Arch Surg 145: 137-142. [Crossref]

6. Elder DE (2011) Thin melanoma. Arch Pathol Lab Med 135: 342-346. [Crossref]

7. Cooper C, Wayne JD, Damstetter EM, Martini M, Gordon J, et al. (2013) A 10-year, single-institution analysis of clinic-pathologic features and sentinel lymph node biopsy in thin melanomas. J Am Acad Dermatol 69: 693-699.

8. Han D, Zager JS, Shyr Y, Chen H, Berry LD, et al. (2013) Clinicopathologic predictors of sentinel lymph node metastasis in thin melanoma. J Clin Oncol 31: 4387-4393. [Crossref]

9. Erdei E, Torres SM (2010) A new understanding in the epidemiology of melanoma. Expert Rev Anticancer Ther 10: 1811-1823. [Crossref]

10. Mihic-Probst D, Shea C, Duncan L, de la Fouchardiere A, Landman G, et al. (2016) Update on Thin Melanoma: Outcome of an International Workshop. Adv Anat Pathol 23: 24-29. [Crossref]
11. Chu VH, Tetzlaff MT, Torres-Cabala CA, Prieto VG, Bassett R, et al. (2013) Impact of the 2009 (7th Edition) AJCC Melanoma Staging System in the Classification of Thin Cutaneous Melanomas. BioMed Res Int. [Crossref]

12. Hieken TJ, Grotz TE, Comfere NI, Inselman JW, Habermann EB (2015) The effect of the AJCC 7th edition change in T1 melanoma substaging on national utilization and outcomes of sentinel lymph node biopsy for thin melanoma. Melanoma Res 25: 157-163. [Crossref]

13. Koskivuo I, Suominen E, Niinikoski J, Talve L (2005) Sentinel node metastasectomy in thin <or=1-mm melanoma. Langenbecks Arch Surg 390: 403-407. [Crossref]

14. Faries MB, Morton DL (2007) Surgery and sentinel lymph node biopsy. Semin Oncol 34: 498-508. [Crossref]

15. Plitas G, Ariyan CE (2012) Controversies in the management of regional nodes in melanoma. J Natl Compr Canc Netw 10: 414-421. [Crossref]

16. Puleo CA, Messina JL, Riker AI, Glass LF, Nelson C, et al. 2005.Sentinel node biopsy for thin melanomas: Which patients should be considered? Cancer Control 12: 230235. [Crossref]

17. Kesmodel SB, Karakousis GC, Botbyl JD, Canter RJ, Lewis RT, et al. (2005) Mitotic rate as a predictor of sentinel lymph node positivity in patients with thin melanomas. Ann Surg Oncol 12: 449-458. [Crossref]

18. Karakousis GC, Gimotty PA, Botbyl JD, Kesmodel SB, Elder DE, et al. (2006) Predictors of regional nodal disease in patients with thin melanomas. Ann Surg Oncol 13: 533-541. [Crossref]

19. Thompson JF, Shaw HM (2006) Is sentinel lymph node biopsy appropriate in patients with thin melanomas: too early to tell? Ann Surg Oncol 13: 279-281. [Crossref]

20. Ranieri JM, Wagner JD, Wenck S, Johnson CS, Coleman JJ 3rd (2006) The prognostic importance of sentinel lymph node biopsy in thin melanoma. Ann Surg Oncol 13: 927932. [Crossref]

21. Cecchi R, Buralli L, Innocenti S, De Gaudio C (2007) Sentinel lymph node biopsy in patients with thin melanomas. J Dermatol 34: 512-515. [Crossref]

22. Warycha MA, Zakrzewski J, Ni Q, Shapiro RL, Berman RS, et al. (2009) Meta-analysis of sentinel lymph node positivity in thin melanoma. Cancer 115: 869-879. [Crossref]

23. Gimotty PA, Guerry D (2010) Prognostication in thin cutaneous melanomas. Arch Pathol Lab Med 134: 1758-1763. [Crossref]

24. Yonick DV, Ballo RM, Kahn E, Dahiya M, Yao K, et al. (2011) Predictors of positive sentinel lymph node in thin melanoma. Am J Surg 201: 324-327. [Crossref]

25. Thompson JF, Soong SJ, Balch CM, Gershenwald JE, Ding S, et al. (2011) Prognostic significance of mitotic rate in localized primary cutaneous melanoma: an analysis of patients in the multi-institutional American Joint Committee on Cancer melanoma staging database. J Clin Oncol 29: 2199-2205. [Crossref]

26. Murali R, Haydu LE, Quinn MJ, Saw RP, Shannon K, et al. (2012) Sentinel lymph node biopsy in patients with thin primary cutaneous melanoma. Ann Surg 255: 128 133. [Crossref]

27. Hinz T, Ahmadzadehfar H, Wierzbicki A, Höller T, Wenzel J, et al. (2012) Prognostic value of sentinel lymph node biopsy in 121 low-risk melanomas (tumor thickness $=1.00 \mathrm{~mm}$ ) on the basis of a long-term follow-up. Eur J Nucl Med Mol Imaging 39: 581-588. [Crossref]

28. Bartlett EK, Gimotty PA, Sinnamon AJ, Wachtel H, Roses RE, et al. (2014) Clark level risk stratifies patients with mitogenic thin melanomas for sentinel lymph node biopsy. Ann Surg Oncol 21: 643-649. [Crossref]

29. Goydos JS (2013) Who should be offered a sentinel node biopsy for melanoma less than $1 \mathrm{~mm}$ in thickness? J Clin Oncol 31: 4385-4386. [Crossref]

30. Mitteldorf C, Bertsch HP, Jung K, Thoms KM, Schön MP, et al. (2014) Sentinel node biopsy improves prognostic stratification in patients with thin (pT1) melanomas and a $\mathrm{n}$ additional risk factor. Ann Surg Oncol 21: 2252-2258. [Crossref]

31. Homolak D, Situm M, Cupic H (2015) Clinico-pathological features of patients with melanoma and positive sentinel lymph node biopsy: A single institution experience. Acta dermatovenerol Croat 23: 122-129. [Crossref]

32. Wat H, Senthilselvan A, Salopek TG (2016) A retrospective, multicenter analysis of the predictive value of mitotic rate for sentinel lymph node (SLN) positivity in thin melanomas. J Am Acad Dermatol 74: 94-101. [Crossref]

33. Hershko DD, Robb BW, Lowy AM, Ahmad SA, Ramadas GH, et al. (2006) Sentine lymph node biopsy in thin melanoma patients. J Surg Oncol 93: 279-285. [Crossref] 
34. Murali R, Scolyer RA, Thompson JF (2012) Can we better identify thin cutaneous melanomas that are likely to metastasize and cause death? Ann Surg Oncol 19: 3310 3312. [Crossref]

35. Conway WC, Faries MB, Nicholl MB, Terando AM, Glass EC, et al. (2009) Agerelated lymphatic dysfunction in melanoma patients. Ann Surg Oncol 16: 1548-1552. [Crossref]

36. Kalady MF, White RR, Johnson JL, Tyler DS, Seigler HF (2003) Thin melanomas: Predictive lethal characteristics from a 30-year clinical experience. Ann Surg 238: 528537. [Crossref]

37. Gimotty PA (2004) Thin primary cutaneous malignant melanoma: A prognostic tree for 10-year metastasis is more accurate than American Joint Committee on Cancer Staging. J Clin Oncol 22: 3668-3676. [Crossref]

38. Han D, Yu D, Zhao X, Marzban SS, Messina JL, et al. (2012) Sentinel node biopsy is indicated for thin melanomas â\%o $¥ 0.76 \mathrm{~mm}$. Ann Surg Oncol 19: 3335-3342. [Crossref]

39. Cordeiro E, Gervais MK, Shah PS, Look Hong NJ, Wright FC (2016) Sentinel Lymph Node Biopsy in Thin Cutaneous Melanoma: A Systematic Review and MetaAnalysis. Ann Surg Oncol 23: 4178-4188. [Crossref]

40. Litzner BR, Etufugh CN, Stepenaskie S, Hynan LS, Cockerell CJ (2012) Mitotic rate in cutaneous melanomas $\leq 1 \mathrm{~mm}$ in thickness: a prospective study. Am J Dermatopathol 34: 827-832. [Crossref]

41. Kelly JW, Sagebiel RW, Clyman S, Blois MS. 1985. Thin level IV malignant melanoma: a subset in which level is the major prognostic indicator. Ann Surg 202: 98-103. [Crossref]

42. Naruns PL, Nizze JA, Cochran AJ, Lee MB, Morton DL (1986) Recurrence potential of thin primary melanomas. Cancer 57: 545-548. [Crossref]

43. Shaw HM, McCarthy WH, McCarthy SW, Milton GW (1987) Thin malignant melanomas and recurrence potential. Arch Surg 122: 1147-1150. [Crossref]

44. Slingluff CL Jr, Vollmer RT, Reintgen DS, Seigler HF (1988) Lethal "thin" malignant melanoma. Identifying patients at risk. Ann Surg 208: 150-161. [Crossref]

45. Woods JE, Soule EH, Creagan ET (1983) Metastasis and death in patients with thin melanomas (less than 0.76 mm). Ann Surg 198: 63-64. [Crossref]

46. Wright BE, Scheri RP, Ye X, Faries MB, Turner RR, et al. (2008) Importance of sentinel lymph node biopsy in patients with thin melanoma. Arch Surg 143: 892-899. [Crossref]

47. Bagaria SP, Ray PS, Joseph RW, Heckman MG, Rawal B, et al. (2013) Ultrathin primary is a marker for worse prognosis in lymph node-positive cutaneous melanoma. Cancer 119: 1860-1867. [Crossref]
48. Vecchiato A (2016) Long-term survival of patients with invasive ultra-thin cutaneous melanoma: A single center retrospective analysis. Medicine (Baltimore) 95: e2452.

49. Shaw HM, McCarthy WH, McCarthy SW, Milton GW (1987) Thin malignant melanomas and recurrence potential. Arch Surg 122: 1147-1150. [Crossref]

50. Veronesi U, Cascinelli N (1991) Narrow excision (1-cm margin). A safe procedure for thin cutaneous melanoma. Arch Surg 126: 438-441. [Crossref]

51. Mori M, Sugiura M, Kono M, Matsumoto T, Sawada M, et al. (2013) Clinicopathologic analysis of 66 Japanese thin melanomas with metastasis of sentinel or regional lymph node. J Cutan Pathol 40: 1027-1034. [Crossref]

52. Venna SS, Thummala S, Nosrati M, Leong SP, Miller JR 3rd, et al. (2013) Analysis of sentinel lymph node positivity in patients with thin primary melanoma. $J$ Am Acad Dermatol 68: 560-567. [Crossref]

53. Gershenwald JE, Thompson W, Mansfield PF, Lee JE, Colome MI, et al. (1999) Multiinstitutional melanoma lymphatic mapping experience: the prognostic value of sentinel lymph node status in 612 stage I or II melanoma patients. J Clin Oncol 17: 976-983. [Crossref]

54. Nahabedian MY, Tufaro AP, Manson PN (2003) Sentinel lymph node biopsy for the T1 (thin) melanoma: is it necessary? Ann Plast Surg 50: 601-606. [Crossref]

55. Sondak VK, Taylor JM, Sabel MS, Wang Y, Lowe L, et al. (2004) Mitotic rate and younger age are predictors of sentinel lymph node positivity: lessons learned from the generation of a probabilistic model. Ann Surg Oncol 11: 247-258. [Crossref]

56. Moser J, Moshammer R, Koglbauer G, Kitzwögerer M, Bachner M, et al. (2016) Sentinel node biopsy in melanoma: a single-centre experience with 216 consecutive patients. Br J Dermatol 174: 889-891. [Crossref]

57. Cochran AJ (1968) Method of assessing prognosis in patients with malignant melanoma. Lancet 2: 1062-1064. [Crossref]

58. Warycha MA, Zakrzewski J, Ni Q, Shapiro RL, Berman RS, et al. (2009) Meta-analysis of sentinel lymph node positivity in thin melanoma. Cancer 115: 869-879. [Crossref]

59. Mozzillo N, Pennacchioli E, Gandini S, Caracò C, Crispo A, et al. (2013) Sentinel node biopsy in thin and thick melanoma. Ann Surg Oncol 20: 2780-2786. [Crossref]

60. Vuylsteke RJ, van Leeuwen PA, Statius Muller MG, Gietema HA, Kragt DR, et al 2003. Clinical outcome of stage I/II melanoma patients after selective sentinel lymph node dissection: ling-term follow-up results. J Clin Oncol 21: 1057-1065. [Crossref]

61. Gershenwald JE, Coit DG, Sondak VK, Thompson JF (2012) The challenge of defining guidelines for sentinel lymph node biopsy in patients with thin primary cutaneous melanomas. Ann Surg Oncol 19: 3301-3303. [Crossref]

Copyright: (C2016 Rodriguez Otero JC. This is an open-access article distributed under the terms of the Creative Commons Attribution License, which permits unrestricted use, distribution, and reproduction in any medium, provided the original author and source are credited. 